- This is a postal questionnaire survey of the working patterns of professionals complementary to dentistry (PCDs) in general dental practices in the South West of England.

- The numbers, working patterns and training experiences of PCDs are described.

- The high vacancy and turnover rates for PCDs point to problems of recruitment and retention.

- The majority of dentists hold favourable attitudes to increasing the training and use of PCDs.

- An estimate is made for the future training needs of PCDs.

\title{
The workforce of professionals complementary to dentistry in the general dental services: a survey of general dental practices in the South West
}

\author{
A. Sprod ${ }^{1}$ and J. Boyles ${ }^{2}$
}

\begin{abstract}
Objective To describe the working patterns, training experiences, estimated size, and future training needs of the workforce of professionals complementary to dentistry in the general dental service in an English region.

Methods Postal questionnaire of NHS dental practices in the South West of England.

Results The response rate was 65\%. There was an average of two whole time equivalent (wte) dentists working per practice. Dentists work a mean 0.8 wte per practice. Sixty per cent of practice time is NHS. Vacancies existed for 120 dentists (98 wte) with reported difficulties in recruitment. There was an average of 1.25 wte dental nurses per dentist with $44 \%$ of nurses working part-time. A quarter of nurses' time is on non-clinical duties. The turnover rate for nurses was between $13 \%$ and $26 \%$, with recruitment difficulties. Approximately $50 \%$ of nurses do not have a professional qualification. There is variation between health authorities in proportions of qualified nurses. Hygienists are employed in $72 \%$ of practices, but only $20 \%$ of their work is NHS. Dentists have favourable attitudes to an expansion in the employment and training of professionals complementary to dentistry.

Conclusions There are problems with recruitment and retention of all categories of the dental workforce in the GDS, particularly in rural areas. There is a large unmet need for pre- and post-qualification training for professionals complementary to dentistry compounded by marked inequalities in access to training.
\end{abstract}

\section{INTRODUCTION}

Attention to the development and deployment of professionals complementary to dentistry (PCDs) has waxed and waned over the past 90 years. ${ }^{1}$ It has long been recognised that the deployment of a full range of a different skill-mix in dental teams can provide acceptable and high quality dental services more costeffectively than services provided by dentists alone. ${ }^{2-4}$ Despite this evidence, the movement towards developing such dental

${ }^{1}$ Senior Research Fellow Dental Public Health, University of Bristol Dental School ${ }^{2}$ Consultant in Dental Public Health, Avon, Gloucestershire and Wiltshire Health Authority, King Square, Bristol

${ }^{*}$ Correspondence to: Andrew Sprod, Dental Public Health, University of Bristol Dental School, Lower Maudlin Street, Bristol BS1 2LY

Email: andy.sprod@bristol.ac.uk teams in the general dental services in the UK has until recently ${ }^{5}$ been limited.

Recent reports have focused attention on the potential for developing the dental team in the UK including the Nuffield Report on the education and training of personnel auxiliary to dentistry, ${ }^{6}$ the Dental Auxiliary Review Group's proposal to expand the categories and range of duties of PCDs, ${ }^{7}$ the Department of Health's report recommending the need for a more flexible workforce ${ }^{8}$ and the proposal to expand the range of duties which can be performed by an increased range of PCDs. ${ }^{9}$ These reports come at a time of increasing problems in accessing NHS dental care, changes in training funding streams ${ }^{10}$ and the ways of training ${ }^{11}$ for PCDs.

Proposals to increase use of PCDs in the UK dates back at least 20 years $^{12}$ and it would seem that the environment for implementing such proposals is now right. The roles, numbers and training of PCDs in the UK therefore may change rapidly and there is a need for collating relevant information to assist in effective planning for these changes. As it is difficult to predict the required numbers of dentists to meet the populations' long-term future needs and demands for dental treatment, ${ }^{13,14}$ one of the advantages of expanding the roles and training capacity for PCDs is that they provide a more flexible workforce than dentists working alone. ${ }^{14-16}$ Their training period is shorter and can be provided in a wider variety of settings.

For effective planning of PCD training, information is required on the present dental workforce. This includes the working patterns of dental teams, the training experiences of PCDs and their commitment to a career in dentistry. Previous surveys have focused on the working practices of individual groups of PCDs, ${ }^{17-22}$ whereas little work has been done to explore working arrangements in the general dental services. ${ }^{23}$

Workforce Development Confederations (WDCs) hold the budget for training of clinical professions working in the mainstream NHS. The lead confederation for dentistry in the South West commissioned this survey with the objectives to:

- Estimate the current size of the PCD workforce in the South West GDS.

- Describe the working patterns, training experiences and career pathways of PCDs in the South West GDS.

- Determine attitudes of dentists to working with a broader range of expanded duty PCDs, and

- Estimate the future training needs for PCDs in the South West. 


\section{METHODS}

\section{Population}

The target population was the dental workforce working in NHS general dental services in the South West Region. The dental workforce was defined as dentists, dental nurses, dental hygienists/dental therapists, dental laboratory technicians, receptionists and practice managers working in general dental practices.

\section{Study population and sample}

The study population was individual practices in the South West and all practices providing NHS treatment at the time of the survey were included in the sample. The study population was identified using a database of individual general dental practitioners (GDPs) produced by the Dental Practice Board (DPB) for the Department of Health (DoH). The Department of Health releases the database to each of the NHS Regions. Permission to use the database was gained from the South West Region, the Department of Health and the Dental Practice Board after explaining the purpose and nature of the survey to each of these parties.

The basis of individual record entries to the database is claims made by dentists to the Dental Practice Board in the previous year. Database fields include name of dentist, practice address, health authority and date of entry to health authority list. The database was sorted by health authority and by postal addresses. Only one questionnaire was sent to each identified dental practice address. Where more than one dentist worked at one address, the record of the dentist with the earliest date of entry was selected. The questionnaire was personally addressed to the dentist selected by the above method. All identified practices were included in the sample.

\section{Questionnaire}

The survey method employed was a self-complete 69 item postal questionnaire. The questionnaire was developed after a literature review and discussions with colleagues in dental public health, general dental practice, hygienists, dental nurses and dental therapists and those involved in training PCDs. Some questions were derived from a telephone questionnaire of GDPs in the West Midlands, others from a previous unpublished local survey of GDPs, and others were developed by the authors. The questionnaire was pre-tested on members of the Local Dental Committee and other local general dental practitioners. Eligible practitioners involved in pre-testing the questionnaire were not excluded from the survey. The questionnaire consisted of seven sections covering: practice details; activities of each practice's dentists; the numbers, training and working experiences of dental nurses, dental hygienists, dental technicians, administrative staff and finally dentists' attitudes to future roles, employment and training of PCDs. Definitions of terms such as a 'session' (a full morning, afternoon or evening) were included in the questionnaire. The questionnaire consisted of both categorical (coded) and continuous (numerical) closed questions. Other than a subjective assessment of face and content validity in the process of pretesting, no other methods of assessing validity or reliability were conducted.

\section{Administration of questionnaire}

The survey was conducted in two waves. The first wave was posted on the same day in June 1999 together with a covering letter and postage-paid return envelopes. Each questionnaire was identifiable through unique codes. Entrance into a draw for two prizes of book tokens was offered as an incentive for respondents. Records of responding subjects were maintained and all non-respondents received a reminder questionnaire one month later.
Table 1 Response rates by health authority area

\begin{tabular}{lccl}
\hline HA area & Adjusted sample $(\mathrm{n})$ & Total response after two waves $\mathrm{n} \%$ \\
\hline Avon & 158 & 94 & 59 \\
Cornwall & 72 & 56 & 78 \\
Dorset & 128 & 85 & 66 \\
Glos & 92 & 66 & 72 \\
NE Devon & 72 & 47 & 65 \\
Somerset & 67 & 41 & 61 \\
SW Devon & 96 & 62 & 65 \\
Wiltshire & 85 & 50 & 59 \\
Total & 770 & 501 & 65
\end{tabular}

\section{Data entry and analysis}

A data entry form was designed using PinPoint software. A research assistant entered the data as forms were returned. The entered data was exported to SPSS version 10.0 for data analysis, which was undertaken by the lead author. Analysis for this paper was restricted to descriptive statistics, with limited analysis of qualitative data.

\section{Non-respondents}

A follow-up telephone survey was undertaken of 20 randomly sampled non-responding practices to determine if there were major differences between the responding and non-responding population. The characteristics of the population of non-responding practices was compared with the population of responding practices by numbers of dentists working per practice.

Results are presented by the responding population and projections made from these to make estimations about the dental workforce for the whole GDS in the region.

\section{RESULTS}

\section{Response rate}

Seven hundred and seventy eight practices were identified, 386 responded in the first wave and 115 in the second. Eight addresses were no longer dental practices, giving an adjusted sample of 770 and response rate of $65 \%(n=501)$. This is in line with the mean response rate to postal surveys by GDPs. ${ }^{24}$ There were differences in responses by HA, ranging from $59 \%$ to $78 \%$ (see Table 1). No response bias was detected in the follow-up of non-responders, justifying the projection of findings to the South West GDS as a whole.

A proportion of the workforce work in two or more practices, so estimates of absolute numbers will include some double-counting of individuals. A more accurate reflection of the size of the workforce is through the currency of whole time equivalents (wte).

\section{Dentists, practice size and whole time equivalents}

The number of dentists working in the responding practices was 1,214 , equivalent to $70 \%$ of the region's 1,728 dentists (DPB database). The mean number of dentists per practice was 2.42 (Table 2), 156 practices (31\%) were single-handed (Figure 1), and 38\% had three or more dentists. The only significant difference between HAs (independent sample 2-tailed $t$-test $\mathrm{p}=0.001$ ) was between Avon and Dorset. There was no significant difference in the mean number of dentists per practice in the responding group and the non-responding group.

Tables 1 and 2 were used to estimate the total dentist workforce in the South West using the currency of "whole time equivalents' (wte), 1 wte is equivalent to 10 sessions a week. Wtes are used to describe the relative working arrangements of PCDs to dentists. Estimating the regional dental workforce (Table 2) assumes the non-responders are similar to the responders, where:

Total wte dentist workforce $=$ total no. of practices $\mathrm{x}$ mean dentist wte/practice. 


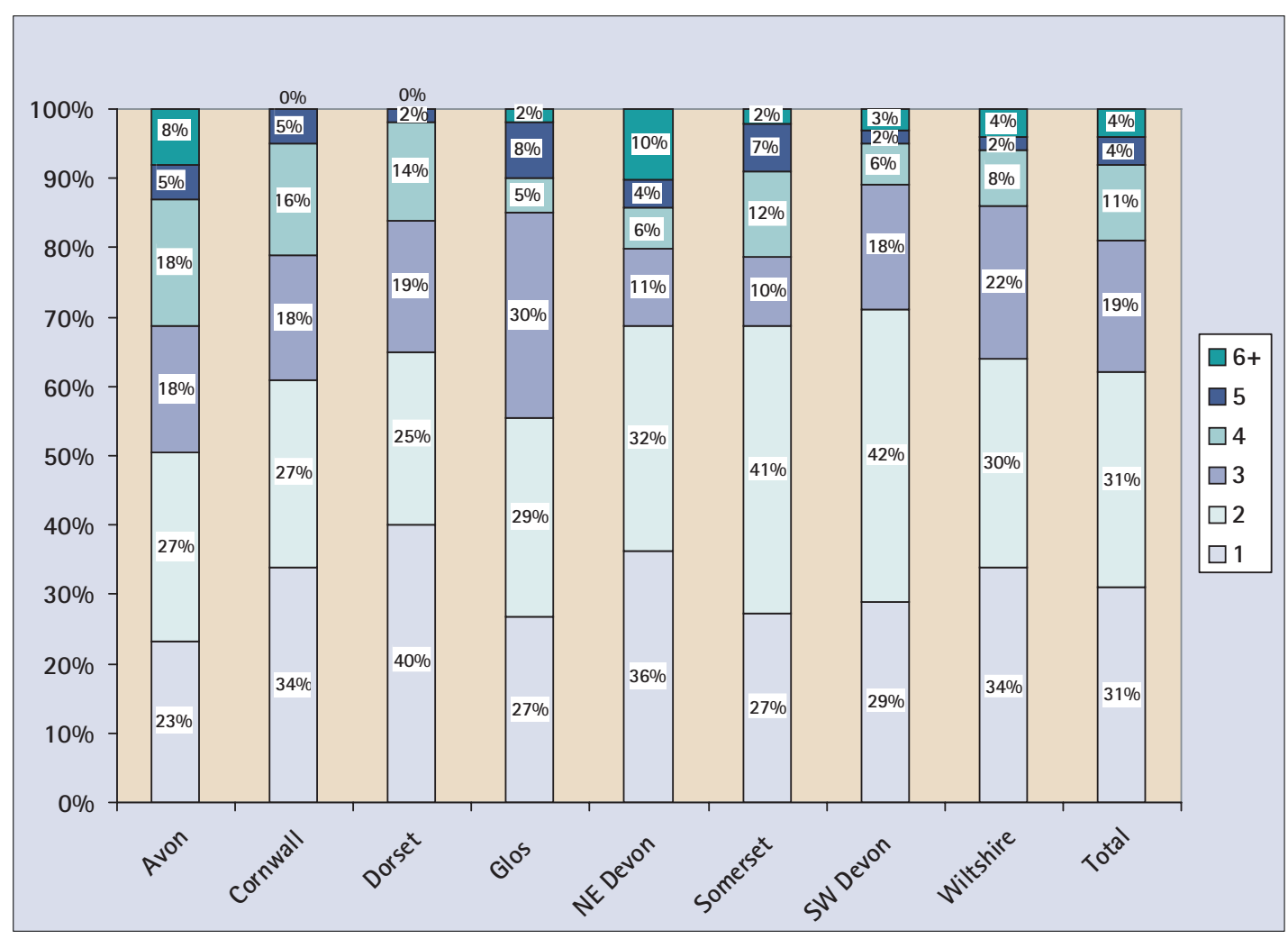

Figure 1 Distributions of practices by numbers of dentists per practice

\section{Specialists in practice}

At least one dentist restricted work to one specialty in 50 practices. Thirty-three spent up to 33\% of their time, 1 spent $50 \%$, and 16, all of their time on specialist practice. Specialist-only practices were as likely to be single-handed as other practices. Thirty one per cent $(n=5)$ were single-handed and 69\% $(n=11)$ had two or more dentists.

There was a total of 54 specialists, $36(72 \%)$ were orthodontists, 12 (24\%) restorative specialists and $6(12 \%)$ oral surgeons. The mean wte per practice of specialist dentists was 0.79 .

\section{Numbers of patients and proportion of time spent on NHS contracts}

Four hundred and ninety four respondents (99\%) completed questions about practice premises. Three hundred and ninety five $(80 \%)$ practices had more than one surgery, $50(10 \%)$ had four or more surgeries, $81(16.9 \%)$ had increased the surgeries in their practice during the previous two years and $100(20.2 \%)$ were considering this. Of those who had expanded, 20 (24.7\%) had a dentist vacancy.

Four hundred and sixty nine respondents (94\%) completed questions about patient lists. The total patients (NHS and private) seen by these practices was 2,410,235 (mean $=5,139$ per practice). The mean proportion of clinical time on NHS dentistry per practice was $57.24 \%$ (range $0-100 \%$, mode $=90 \%$ ). There were no significant differences between HAs in proportion of time on NHS work. Time may not reflect proportion of patients or proportion of income.

Five hundred (99.8\%) answered questions about current dentist vacancies, $81(16.2 \%)$ had at least one vacancy, with a total of 636 vacant sessions available (64 wte). The mean vacant sessions per practice was 8 (mode $=10$ ). There were differences by $\mathrm{HA}$ in the proportion of practices with vacancies (see Table 3 ). There was an estimated 98 wte spare capacity in the whole region.

Table 2 Mean number of dentists, total clinical sessions and whole time equivalent (wte1) dental workforce per practice, by health authority

\begin{tabular}{|c|c|c|c|c|c|c|c|}
\hline HA Area & $\begin{array}{l}\text { Total number of dentists } \\
\text { in responding practices }\end{array}$ & $\begin{array}{l}\text { Mean number of } \\
\text { dentists per practice }\end{array}$ & $\begin{array}{l}\text { Total number of sessions } \\
\text { worked in responding practices }\end{array}$ & $\begin{array}{l}\text { Mean number of } \\
\text { sessions per dentist }{ }^{2}\end{array}$ & Mean wte per practice ${ }^{3}$ & $\begin{array}{l}\text { Total number of } \\
\text { practices in area }\end{array}$ & $\begin{array}{l}\text { Estimated Total } \\
\text { dentist work- } \\
\text { force wte in area }\end{array}$ \\
\hline Avon & 268 & 2.85 & 2,076 & 7.7 & 2.2 & 158 & 347.6 \\
\hline Cornwall & 130 & 2.32 & 1,062 & 8.2 & 1.9 & 72 & 136.8 \\
\hline Dorset & 182 & 2.14 & 1,568 & 8.6 & 1.9 & 128 & 243.2 \\
\hline Glos & 162 & 2.45 & 1,288 & 8.0 & 2.0 & 92 & 184 \\
\hline NE Devon & 117 & 2.49 & 911 & 8.2 & 1.9 & 72 & 136.8 \\
\hline Somerset & 99 & 2.41 & 792 & 7.9 & 1.9 & 67 & 127.3 \\
\hline SW Devon & 142 & 2.29 & 1,077 & 7.7 & 1.7 & 96 & 163.2 \\
\hline Wiltshire & 114 & 2.28 & 982 & 8.6 & 2.0 & 85 & 170 \\
\hline Total & 1,214 & 2.42 & 9,756 & 8.0 & 1.96 & 770 & 1,509 \\
\hline \multicolumn{8}{|c|}{$\begin{array}{l}1=\text { wte }=\text { whole time equivalent, } \text { where } 1 \text { wte }=10 \text { clinical sessions worked by dentists } \\
2=\text { Total number of sessions worked in responding practices } / \text { total number of dentists } \\
3=\text { (Total number of sessions in responding practices } / \text { total number of practices }) / 10 \\
4=\text { Includes responding and non-responding practices } \\
5=\text { Mean wte per practice } x \text { total number of practices in area }\end{array}$} \\
\hline
\end{tabular}


Table 3 Current vacancies for dentists and number of vacant sessions by health authority

\begin{tabular}{|c|c|c|c|c|c|c|}
\hline \multirow[t]{2}{*}{$\mathrm{HA}$} & \multirow[b]{2}{*}{$n$} & \multicolumn{2}{|c|}{ Number of practices with vacancies ${ }^{a}$} & \multirow{2}{*}{$\begin{array}{l}\text { Total number of sessions available } \\
\qquad n\end{array}$} & \multirow{2}{*}{$\begin{array}{l}\text { wte dentists } \\
\text { wte }\end{array}$} & \multirow{2}{*}{$\begin{array}{l}\text { Estimated total wte vacancies }{ }^{1} \\
\text { wte }\end{array}$} \\
\hline & & n & $\%$ & & & \\
\hline Avon & 94 & 8 & 8.5 & 54 & 5.4 & 9.2 \\
\hline Cornwall & 56 & 15 & 26.8 & 127 & 12.7 & 16.6 \\
\hline Dorset & 85 & 7 & 8.2 & 37 & 3.7 & 5.6 \\
\hline Glos & 66 & 5 & 7.7 & 37 & 3.7 & 5.2 \\
\hline NE Devon & 46 & 9 & 19.1 & 61 & 6.1 & 6.5 \\
\hline Somerset & 41 & 18 & 43.9 & 151 & 15.1 & 25.0 \\
\hline SW Devon & 62 & 10 & 16.1 & 84 & 8.4 & 13.3 \\
\hline Wiltshire & 50 & 8 & 16 & 85 & 8.5 & 14.6 \\
\hline Total & 500 & 80 & 16.0 & 636 & 63.6 & 98.5 \\
\hline
\end{tabular}

Table 4 Number and wte of dental nurses (dn) by health authority

\begin{tabular}{|c|c|c|c|c|c|c|c|}
\hline \multirow[t]{2}{*}{ HA Area } & \multirow{2}{*}{$\frac{\text { Total DNs }}{n}$} & \multicolumn{2}{|c|}{ Number of part-time DNs } & \multirow{2}{*}{$\begin{array}{c}\text { Number of DNs per practice } \\
\text { mean }\end{array}$} & \multirow{2}{*}{$\begin{array}{c}\text { Total sessions per week } \\
n\end{array}$} & \multirow{2}{*}{$\frac{\text { DN wte per practice }}{\text { wte }}$} & \multirow[t]{2}{*}{ Mean wte per nurse } \\
\hline & & $n$ & $\%$ & & & & \\
\hline Avon & 329 & 148 & 45 & 3.5 & 2341 & 2.5 & 0.71 \\
\hline Dorset & 270 & 108 & 40 & 3.2 & 2028 & 2.4 & 0.75 \\
\hline Glos & 219 & 83 & 38 & 3.4 & 1613 & 2.5 & 0.74 \\
\hline NE Devon & 172 & 90 & 52 & 3.7 & 1302 & 2.8 & 0.76 \\
\hline Somerset & 149 & 81 & 54 & 3.6 & 1114 & 2.7 & 0.75 \\
\hline SW Devon & 182 & 93 & 51 & 2.9 & 1491 & 2.4 & 0.82 \\
\hline Wiltshire & 148 & 49 & 33 & 3.0 & 1156 & 2.3 & 0.78 \\
\hline Total & 1637 & 726 & 44 & 3.3 & 12353 & 2.5 & 0.75 \\
\hline
\end{tabular}

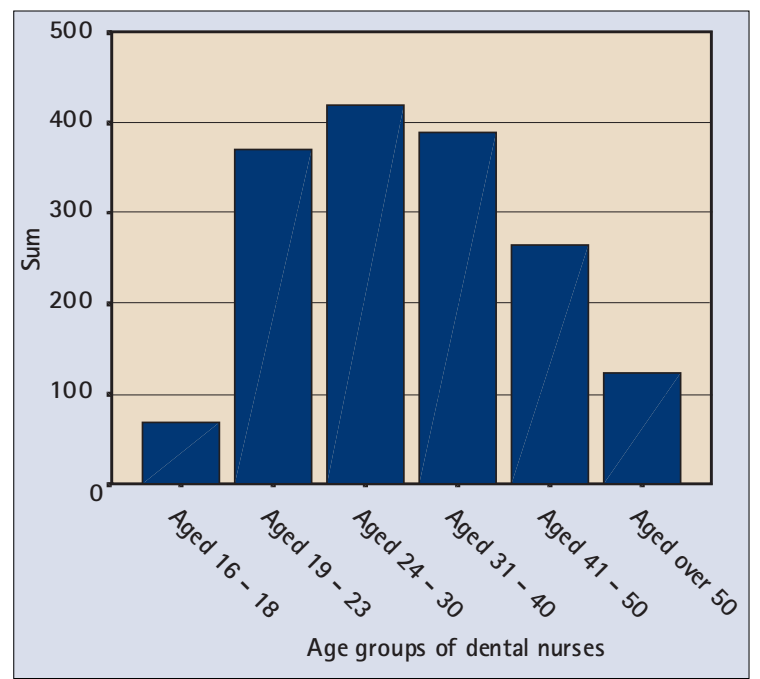

Fig 2 Age Dental nurses

distribution The number of dental nurses (DNs) working in responding practices of dental nurses was 1,637 , (mean $=3.3$ DNs per practice), 44\% worked part-time, and the mean wte per DN was 0.75. The mean DN wte per practice was 2.5, compared with a mean dentist wte per practice of 1.96 (see Table 2), giving a wte ratio of 1.25 DNs per dentist (see Table 4).

The estimated total DN workforce in the region was 1,906 wte, provided by 2,500 DNs. It is not clear whether the 98 wte unfilled dentist vacancies also required additional DNs to be recruited to support them. If they did, the estimated total DN workforce capacity becomes 2,028 wte, or 2,700 DNs (working at 0.75 wte), requiring up to 200 additional DNs for the region.

Forty three per cent of DNs also worked on non-clinical duties (eg reception). These duties occupied 24\% of their time and amounted to 302 wte (465 wte for the whole region). Excluding these duties, the clinical dentist:DN wte ratio is $1: 1$.

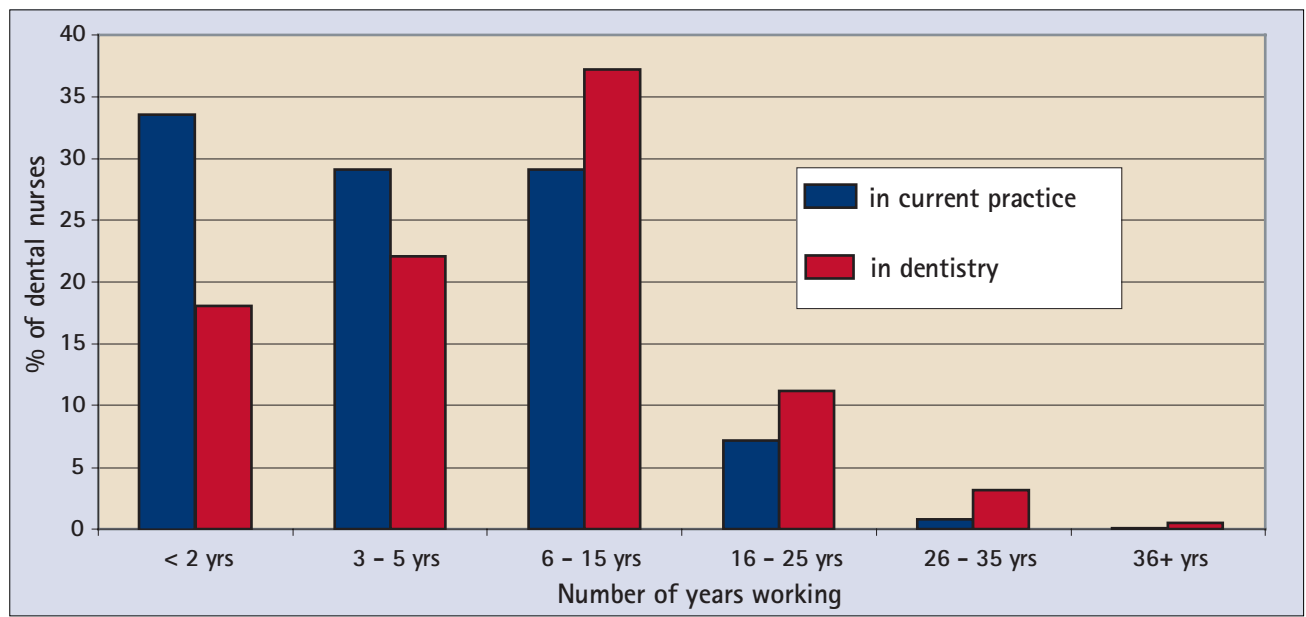

Fig 3 Distribution of dental nurses by years working as dental nurse and years working in current practice. 


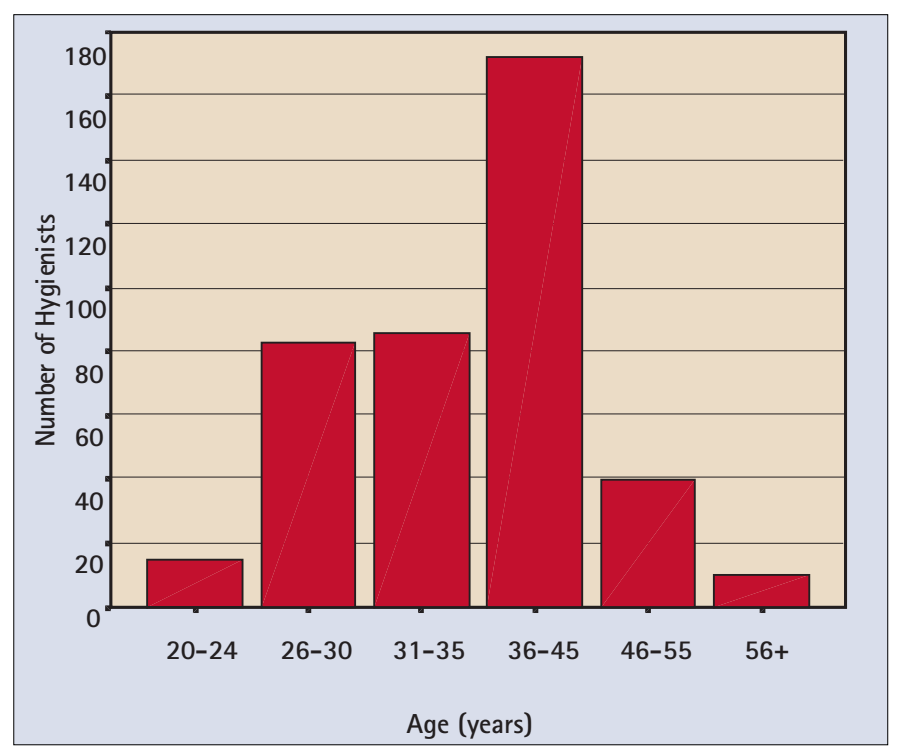

Fig 4 Age distribution of dental hygienists

The mode age of DNs was 24 - 30 years (Figure 2). The mode number of years spent working as a DN (Figure 3), was $6-15$ years $(37.2 \%, n=609), 15 \%$ had worked as a DN for more than 15 years. The mode time worked in their current practice was less than two years.

Eight hundred and two (49\%) DNs held the National Certificate of Dental Nursing. The only geographic significant difference (Pearson Chi-squared 2-sided significance $=0.041$ ) was between NE Devon (43.6\%) and Somerset (55.0\%). Six hundred and forty one (80\%) gained this qualification within the past 10 years. There are about 1,275 unqualified DNs working in the region.

One hundred and three (12.8\%) qualified DNs held additional certificates, some held more than one, 69 were in oral health education, 64 in dental radiography and 30 in dental conscious sedation.

Six hundred and thirty two (80\%) DNs qualified through evening classes, $99(12.5 \%)$ through dental schools (full- or parttime) and 62 (7.8\%) from 'elsewhere' (armed forces or 'other'). There were geographic variations in how DNs gained qualifications. In Avon they were more likely to have been through the dental school $(39 \%, n=66)$. In other HAs this proportion fell to between 2\% (Cornwall) and 11\% (Wiltshire). An estimated 725 $\mathrm{DNs}$ in the region qualified through evening classes.

\section{Dental nurse vacancies}

Two hundred and fourteen (43\%) practices had had at least one dental nurse vacancy in the previous year. Of these 87 (41\%) had recruitment problems. Forty six (9.2\%) practices had a current vacancy. The minimum DN annual turnover is $13 \%$ (214 of 1,637). The true rate is probably higher. If these are leaving the profession, this rate requires annual recruitment and training of 300 new DNs to maintain the current regional workforce.

\section{Dental hygienists}

Three hundred and fifty eight (71.6\%) practices employed hygienists. There were geographic variations, ranging from 83\% $(n=34)$ in Somerset to 65\% in Gloucestershire $(n=42)$ and Dorset $(n=55)$. Two hundred and sixty nine respondents (75\%) answered further questions on hygienists, of these $64 \%(n=172)$ employed one hygienist, 25\% ( $n=67)$ employed two, 11\% ( $n=30)$ employed more than two and one employed 10. The number of hygienists in these practices was 418 (mean per practice $=1.55$ ), $379(91 \%)$ working part-time. The total number of hygienist sessions was 1,553 (155.3 wte), with a mean 0.57 wte hygienists per practice. In these practices the dentist wte was 595.2, giving a wte ratio of 0.26 hygienist: 1 dentist. Only 276 (17.8\%) hygienist sessions were NHS, with private treatment taking $82 \%$ of their time. Seventy five per cent of hygienists $(n=313)$ provided no NHS sessions at all.

The true number of hygienists was less than 418. Hygienists worked a mean of 0.37 wte in each practice and many would work in several practices and be double-counted. It was not possible to estimate how many hygienists work between two or more practices.

Larger practices are more likely to employ hygienists, 63\% with two or more dentists employ hygienists, compared with $33 \%$ of single-dentist practices. The average number of dentists in dental hygienist practices $(n=358)$ was 2.70 . In practices with no hygienists $(\mathrm{n}=143)$ the mean number of dentists was 1.70 . Practices with hygienists, tended to have more surgeries (mean $=3$ ) than those with no hygienists (mean $=1.8$ ).

Eighty four per cent of hygienists were between 20 and 45 years old (Figure 4). They tend to be older and stay in the profession longer than DNs (Figure 5). More than 50\% were over 35, and 60\% stayed in the profession for more than 10 years. Many change practices frequently, $60 \%$ had been in their current practice for less than five years and $40 \%$ less than three years.

Three hundred and seventy (87\%) hygienists held the Diploma in Dental Hygiene, 36 (8.4\%) were trained as dental therapists, 5 (1.2\%) as dentists, and $16(3.7 \%)$ held qualifications from other countries.

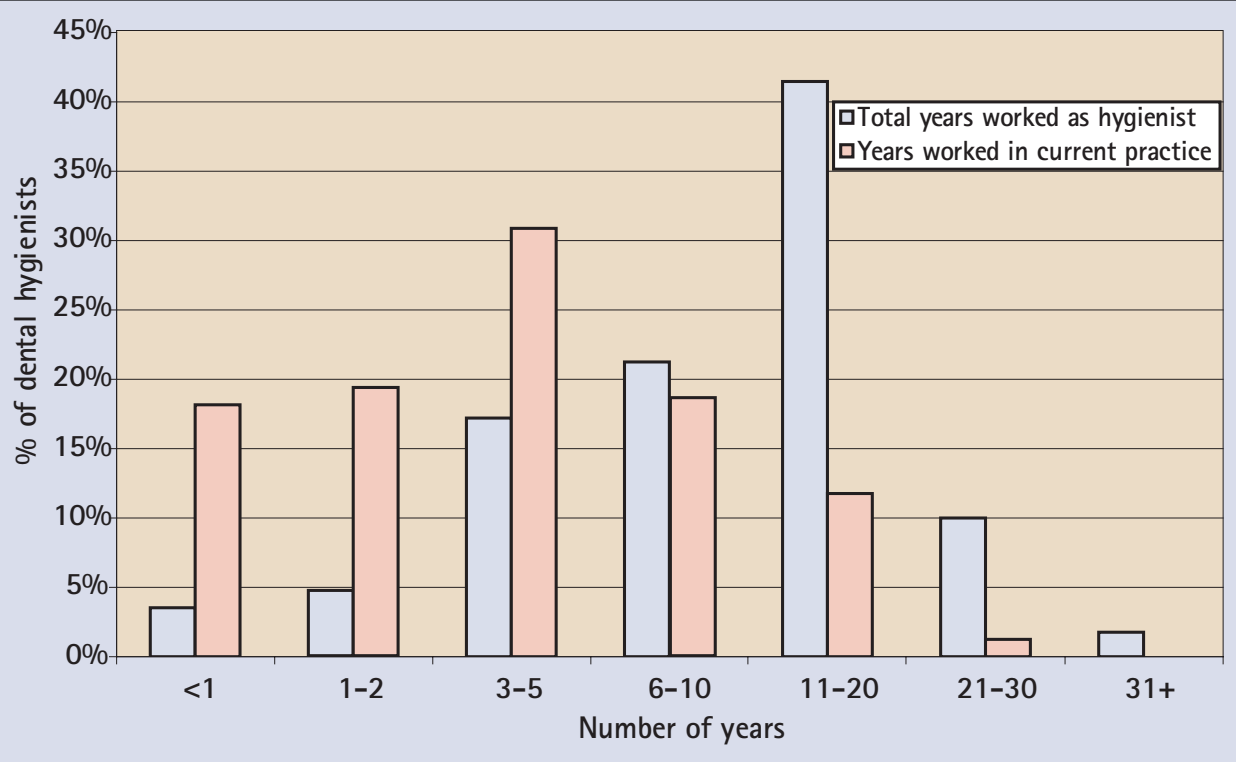

Figure 5 Distribution of dental hygienists by years working as dental hygienist and years working in current practice. 


\section{Vacancies and Recruitment of Hygienists}

One hundred and fourteen hygienist practices (23\%) had a vacancy during the previous year, $82(72 \%)$ had a recruitment problem, whilst $54(47 \%)$ had a current vacancy. In addition six practices that had not previously employed a hygienist, were trying to recruit one. The estimated annual hygienist turnover rate was $25 \%$.

\section{Other personnel}

Forty practices (8\%) employed 43 oral health educators, working a total of 72 sessions per week (7.2 wte), and a mean of 1.7 sessions per week per practice. A total of 70 dental technicians worked from the premises of $38(7.6 \%)$ practices (mean $=1.8$ per practice).

In contrast, $80 \%(n=399)$ of practices employed a receptionist. There were a total of 766 receptionists in this group (1.9 per practice), working a total of 5,761 sessions per week (576.1 wte, 0.75 wte per receptionist and 1.4 wte per practice). Four hundred and eighty one (63\%) receptionists worked part-time, working on average 0.6 wte. Practices that did not employ receptionists tended to be smaller practices with one or two dentists (mean number of dentists in this group $=1.77$, mode $=1$ ), compared with those that did employ receptionists (mean number of dentists $=2.59$, mode $=2$ ).

There were 217 practice managers in 201 (40\%) practices (mean $=1.1$ per practice) working a total of 1,574 sessions per week (157.4 wte, 0.8 wte per practice and 0.7 wte per practice manager). One hundred and thirteen (52\%) practice managers worked part-time (mean $=0.47$ wte). Practices employing practice managers were more likely to have more than one dentist (mean $=$ 2.90 dentists per practice, mode $=2$ dentists per practice).

Three hundred and eleven (90\%) practices with more than one dentist employed a receptionist and 173 (50\%) practice managers, compared with single-handed practices where 103 (66\%) employed receptionists and 58 (38\%) practice managers.

Six hundred and thirty two (64.3\%) practice managers and receptionists were over 35, and 590 (60\%) had worked less than 10 years in dentistry, suggesting this group come to the dental sector later in life. However, 199 (20\%) had DN qualifications, one was a hygienist and four were dental therapists, suggesting that receptionist or practice management work is an option for some PCDs.

\section{Attitudes to expanded duty professionals complementary to dentistry}

The final section covered attitudes to employment and training of expanded duty PCDs (Table 5). There was least support for clinical technicians with $34.2 \%(n=171)$ agreeing there would be a role for them in their practice and 52.2\% $(\mathrm{n}=264)$ disagreeing, $22.3 \%$ ( $n=111)$ would employ one if the law changes. More $(43.5 \%$, $\mathrm{n}=217)$ felt there was a role for therapists, and $37.5 \%(\mathrm{n}=185)$ could employ one.

Hygienists were strongly supported, 82\% $(n=406)$ agreed they had a role in their practice. The response to the statement 'The reason I do not employ a hygienist is because I do not have the space in my practice' was answered by $140(98 \%)$ of the practices that did not employ one and $213(60 \%)$ practices that already did. Of those that did not employ a hygienist, 53\% ( $=$ 74) agreed or strongly agreed with this statement, whilst $20 \%$ of the 'hygienist' practices agreed with it. This may indicate that they would employ more hygienists if they had more space.

There was strong support (66\%) for giving opportunities to hygienists to extend their role to that of a therapist and little disagreement (16\%). Support for making more training opportunities available for PCDs was high $(75.5 \% \mathrm{n}=375)$. Sixty three per cent $(n=312$ ) would be prepared to financially support continued PCD training, with 20\% $(n=97)$ disagreeing. Finally, there was uncertainty about expanding the roles of PCDs, with $30 \%$ ( $\mathrm{n}=150$ ) neither agreeing or disagreeing that they are looking forward to it. However, 52\% $(n=258)$ were looking forward to expanded roles of PCDs and only 17\% were not.

\section{DISCUSSION}

The main aim of the survey was to estimate pre- and post-qualification training requirements of PCDs, by describing the structure, working arrangements and career pathways of GDS dental teams in the South West. Three key areas are discussed. Firstly, how the findings about dental teams impact on training needs, secondly, the general difficulties in long-term workforce planning and finally, recommendations for short-term solutions to meet identified current PCD training needs.

\section{Dental teams in the South West}

In general the South West GDS consists of a large number of small teams, focused around dentists supported by a PCD work-

Table 5 General dental practitioners' attitudes towards employment and training of expanded duty professionals complementary to dentistry

\begin{tabular}{|c|c|c|c|c|c|c|c|c|c|c|c|}
\hline & \multirow{2}{*}{$\begin{array}{l}\text { No. of } \\
\text { Cases }\end{array}$} & \multicolumn{2}{|c|}{ SA } & \multicolumn{2}{|l|}{ A } & \multicolumn{2}{|c|}{ NO } & \multicolumn{2}{|c|}{ D } & \multicolumn{2}{|c|}{ SD } \\
\hline & & $\mathrm{n}$ & $\%$ & $\mathrm{n}$ & $\%$ & $\mathrm{n}$ & $\%$ & $\mathrm{n}$ & $\%$ & $\mathrm{n}$ & $\%$ \\
\hline $\begin{array}{l}\text { There would be a useful role for a clinical technician in my practice who would } \\
\text { work with patients to make dentures. }\end{array}$ & 500 & 39 & 7.8 & 132 & 26.4 & 65 & 13.0 & 173 & 34.6 & 91 & 18.2 \\
\hline If there was a change in the law my practice would employ a clinical technician. & 497 & 21 & 4.2 & 90 & 18.1 & 100 & 20.1 & 172 & 34.6 & 114 & 22.9 \\
\hline There would be a useful role for a dental therapist in my practice. & 499 & 47 & 9.4 & 170 & 34.1 & 106 & 21.2 & 129 & 25.9 & 47 & 9.4 \\
\hline If there was a change in the law my practice would employ a dental therapist. & 493 & 48 & 9.7 & 137 & 27.8 & 120 & 24.3 & 127 & 25.8 & 61 & 12.4 \\
\hline There is a useful role for hygienists in my practice. & 497 & 259 & 52.1 & 147 & 29.6 & 34 & 6.8 & 43 & 8.7 & 14 & 2.8 \\
\hline $\begin{array}{l}\text { The reason I do not employ a hygienist is because I do not have the space } \\
\text { in my practice. }\end{array}$ & 353 & 50 & 14.2 & 66 & 18.7 & 60 & 17.0 & 73 & 20.7 & 104 & 29.5 \\
\hline $\begin{array}{l}\text { Dental hygienists should have the opportunity to extend their clinical role to } \\
\text { that of a dental therapist. }\end{array}$ & 493 & 117 & 23.7 & 208 & 42.2 & 88 & 17.8 & 60 & 12.2 & 20 & 4.1 \\
\hline $\begin{array}{l}\text { There would be enough work in my practice to employ both a vocational dental } \\
\text { practitioner and a clinical auxiliary. }\end{array}$ & 494 & 56 & 11.3 & 95 & 19.2 & 59 & 11.9 & 169 & 34.2 & 115 & 23.3 \\
\hline $\begin{array}{l}\text { Oral hygiene instruction can be carried out by all members of the dental } \\
\text { team (including receptionists). }\end{array}$ & 497 & 98 & 19.7 & 254 & 51.1 & 26 & 5.2 & 98 & 19.7 & 21 & 4.2 \\
\hline $\begin{array}{l}\text { There should be more opportunities made available for training of professionals } \\
\text { complementary to dentistry. }\end{array}$ & 497 & 125 & 25.2 & 250 & 50.3 & 89 & 17.9 & 27 & 5.4 & 6 & 1.2 \\
\hline $\begin{array}{l}\text { I would be prepared to financially support the continued training of my PCDs } \\
\text { to increase their range of skills. }\end{array}$ & 493 & 89 & 18.1 & 223 & 45.2 & 84 & 17.0 & 67 & 13.6 & 30 & 6.1 \\
\hline I am looking forward to when the roles of PCDs are expanded & 494 & 84 & 17.0 & 174 & 35.2 & 150 & 30.4 & 58 & 11.7 & 28 & 5.7 \\
\hline
\end{tabular}


force. The PCD workforce is largely female. ${ }^{25}$ Many practices have developed a varied skill-mix, including both specialist dentists (mainly orthodontists) and PCDs with specific roles such as hygienists and oral health educators. Larger practices have both a wider skill-mix and better ratios of support staff wte per dentist wte than smaller practices. All staff in larger practices tend to have slightly shorter working weeks compared with those in smaller practices. Larger practices seem to be able to accommodate their staff's other responsibilities or aspirations (such as child-care or leisure activities), and this may give them an advantage in recruitment and retention of staff, particularly for females. ${ }^{26}$

Previous work on the dental workforce ${ }^{27}$ reported that larger practices and the use of dental auxiliaries (PCDs) also offer productivity and efficiency advantages ${ }^{4}$ and reduced number of visits per patient per course of treatment. ${ }^{27}$ Furthermore, dentists that did not employ PCDs (more likely in small practices) tended to feel "too busy'. ${ }^{27}$ Together these factors may help to explain the higher levels of stress and signs of burnout found in dentists in smaller practices. ${ }^{28,29} \mathrm{~A}$ shift towards developing larger practices seems desirable from all perspectives. Although there remains a high proportion of single-handed practices in the South West, it is encouraging that many practices were considering expansion.

\section{Barriers to expansion}

The decision to expand a practice and/or employ PCDs requires an assessment of a variety of factors including: the size and nature of the local population, the population's demands and needs for dental care, the skill-mix required to meet these needs and demands, the ability to recruit and retain staff, the size of their premises, the resources available and financial risks. To a large extent these decisions are likely to be made by individual GDPs based on their own subjective assessments of service demands. GDPs are in an unenviable position as they personally bear both the responsibility for, and risks of, making such decisions. This is probably a major barrier to the development of larger practices, and methods of supporting GDPs through improving needs assessment information and financial support is desirable.

\section{Rural populations}

The size and distribution of the local population is another limiting factor to dental team expansion. The South West has a large rural population with relatively few cities or large towns. Practices based in small towns play an important role in ensuring access to dental services, particularly where local public transport is limited. The catchment population, the local employment pool, and training opportunities are all more restricted than in urban areas, and it is unsurprising that there are both high proportions of singlehanded practices, and more reported problems in recruitment (of all staff) found in those health authorities with large rural populations. In rural areas it may be desirable to move towards developing either larger practices by merging of existing practices, or managed clinical networks linking practices to larger teams located elsewhere. These service models have the potential to provide a wider skill-mix.

\section{Developing services to meet perceived demands}

Although not directly asked about perceptions of 'busyness' which is seen by some authors as a useful indicator of service demand for workforce planning ${ }^{30}$ - practices in the South West appear to be busy. Most have large patient lists and many had either recently increased the number of their surgeries or were considering doing so. However, recruitment of dentists appeared to be a problem for expanding practices as many of the current vacancies and reported difficulties in recruitment, were for these new posts.
The South West is one of the areas in the UK where patients report most difficulty in accessing NHS dental services. ${ }^{31}$ An alternative way of delivering more services to meet service demands is through expanded duty PCDs and, in contrast to views of 20 years ago, ${ }^{32}$ there were generally favourable attitudes to them, with many practices stating they would employ a wider skill-mix of PCDs if their premises were larger. Hygienists are viewed more favourably than other PCDs, and it can be assumed that this is due to dentists' familiarity with their role and their known cost-benefits. ${ }^{30}$ Hygienists tend to work privately in the GDS, most probably to increase their profitability. The profitability of dental therapists is yet to be determined either under the NHS or privately. Systems of remuneration (to achieve attractive incomes for all grades of staff) and available practice space are probably key factors in the future deployment of PCDs in the GDS.

\section{Retention and recruitment}

A major concern is the relatively high turnover of all staff, including dentists, revealed by this survey and others. ${ }^{33}$ On average practices can expect to need to recruit a new dental nurse every two years, a hygienists every four years and a dentist every five years. A high proportion of dental nurses enter and leave the profession at an early age without gaining any relevant qualifications. Retention problems are coupled with perceived difficulties in recruitment of all members of the dental team, particularly in rural areas. The different response rates between health authorities may reflect levels of concern about recruitment, retention and training issues. Response rates tended to be higher in more rural health authorities and in those more distant from the dental school. The dental school is an important factor as it is the only base for training of hygienists, dentists and post-qualification nurses in the region. Furthermore it is not located 'centrally', and the distance to the furthest part of Cornwall is 200 miles.

Problems with recruitment and retention of staff are due to many factors. Recruitment problems could be due to factors such as small pools of local job-seekers, for example in areas with low unemployment and high competition for similarly skilled staff; low wages; poor perceptions about career or long-term prospects; and shortage of local training opportunities.

The high turnover rate (retention) must, at least in part, be due to job dissatisfaction as well as other factors such as levels of income; financial and professional commitment, career breaks, general mobility of the population and other sociodemographic factors. Recent work shows that dental nurses' low job satisfaction are related to feelings of lack of control, being taken for granted and economic dependence. ${ }^{34}$ Dental nursing is relatively low paid compared with most work, and to give a competitive edge in the job market both for recruitment and retention, employers need to consider incentives such as: pay, good working environments and relationships, opportunities for training and flexible working hours. ${ }^{25}$ Interestingly it has been reported that dentists have lower levels of job satisfaction than hygienists or dental therapists, ${ }^{35}$ however their turnover rate is lower probably because of factors such as income. The turnover rate (of the female workforce) is partly explained by career breaks for childcare responsibilities. ${ }^{36} \mathrm{~A}$ high proportion of this group will return to dentistry, and appear to have higher levels of job satisfaction as a result. ${ }^{22}$ This issue will become even more important as the proportion of females in the dental workforce increases.

\section{Long-term workforce planning}

The estimates of training needs from this survey is based largely on the numbers of unqualified personnel (dental nurses); the number of reported vacancies and turnover rates; and self-reported estimates of the capacity of practices to expand and/or increase the 
number of dentists working in them. For short- to medium-term forecasting this simple model is a reasonable method of estimating PCD training needs, as it reveals the current 'gaps' between supply and demand.

Simple models are not helpful for long-term planning because of the large impact of other factors on dental needs and the dental workforce. These factors include: wider political or socio-economic environments (particularly unemployment); demographic changes; changing trends in dental needs and demands and changes in the ways of delivering and remunerating effective services. Clearly, there are limits to predicting long-term trends in any of these factors, and how they may interact. Furthermore, complex models attempting to incorporate them have not been successful in predicting long-term workforce needs, ${ }^{30,37}$ have been criticised for conceptual reasons, ${ }^{13}$ and are unlikely to be useful in the future. ${ }^{38}$ If there is a shift in the way dental services are delivered and the ways staff are trained, as outlined most recently in Options for Change ${ }^{39}$ and by the Audit Commission, ${ }^{40}$ any model for workforce planning becomes yet more complex.

Despite the limitations of long-term forecasting it is useful to gather regular information on workforce training requirements within any system to monitor national and local supply and demand for personnel and to help avoid future over-, or undersupply. This is particularly important where training is of long duration and requires a concentration of specialist skills and resources to deliver it because of the long lead-time plus total training time in producing the required outputs. The longer the training, the more complex the planning model becomes. Ideally, it is desirable to shift towards highly flexible, modular, skill-based, distance-learning methods of training where people can enter and exit the 'skills escalator', as required, to meet both individual (trainee) and society's needs. Arguably, in such a system, the planning to output time for each incremental shift in skills is shorter and therefore less complex.

\section{Recommendations for the short-term}

Less than half of dental nurses were qualified, a finding supported by other recent reviews. ${ }^{23,41}$ When it becomes obligatory for dental nurses to be registered, ${ }^{9}$ they will need to be either qualified, working towards qualification, or able to demonstrate levels of experience and skills to be exempt from pre-qualification training. In itself, this means that there is an urgent need to address access to dental nurse training as a priority together with how it should be delivered and funded. If dentistry is to be brought into line with the rest of the NHS, the responsibility for funding such training rests with the Workforce Development Confederations (WDCs).

Currently, WDCs only fund 16 out of 180 pre-qualification training places for dental nurses per year in the region. Furthermore, all WDC funded pre- and post-qualification training of PCDs takes place in the dental school, which is not easily accessible for much of the region, giving rise to inequality in access to training. Most dental nurse training is provided through a number of smallscale self-funded initiatives across the region, mainly based on evening classes in colleges and undertaken by local GDPs and dental nurses. If there is no change in the way dental services are delivered or remunerated there is a need to train about 300 dental nurses per year in the South West to meet current service needs and turnover rates. This will require funding and developing an extra 100 training places in the region.

At present the WDC funds six dental hygienists per year in the dental school. There is sufficient demand to train $10-20$ hygienists per year for the region, which will require funding an extra 4-16 training places. There are no training places in the South West for dental therapists, however just under half of GDPs in this survey, and others, ${ }^{33}$ state they are prepared to employ them. Factors, which may limit their employment in the GDS in the short-term include: caution about their profitability under the present NHS remuneration, lack of practice space and difficulties in recruitment. Now that dental therapists can work in the GDS, it would be sensible to develop local training for at least 10 therapists per year, with a view to increasing this number over time. It would be preferable to develop modular training of therapists in parallel with hygienists, so that future trainees gain dual qualifications. In addition, it is recommended that existing hygienists have access to this training to gain therapist qualifications.

A group of PCDs which are more difficult to access are dental technicians. This survey only identified a small group of technicians working from dental practice premises and little information was gained about this group. The majority of technicians work in privately run laboratories of varying size and have relatively little contact with the clinical environment of dental practices. The proposed new PCD of clinical technician was the least supported of all the expanded duty PCDs, and there appeared to be more uncertainty about the benefits of employing such personnel in GDS practices. At present there are at least 15 different qualifications which can be gained by dental technicians, yet there is no obligation to hold any. There is an urgent need to review and rationalise training of dental technicians nationally prior to the introduction of registration.

\section{CONCLUSIONS AND RECOMMENDATIONS}

The South West GDS employs an estimated 2,500 dental nurses working 1,906 wtes, 44\% of dental nurses work part-time. There is an average of 3.3 dental nurses per practice, providing a mean 1.25 wte per dentist wte. Less than half of dental nurses are qualified. There are 418 hygienists providing 155 wte, 91\% work part-time and there is a mean of 0.57 hygienists per dental practice, only $20 \%$ of hygienist time is spent on NHS work. There are high turnover rates of all staff in the GDS coupled with recruitment problems, particularly in more rural areas.

Attitudes of dentists to the employment and training of expanded duty professionals complementary to dentistry (PCDs) are generally favourable and 37\% would employ a dental therapist. A major limitation to employing PCDs is the size of dental practice premises and a third of dental practices remain singlehanded. However, a third of practices had either recently expanded or were considering doing so, and only $20 \%$ had only one surgery in their practice.

There is a shortage of training opportunities for all PCDs, with inequalities in access to training. In the short-term, there is a need to develop and fund training places for an extra 100 dental nurses, 10 hygienists and 10 therapists in the region. It would be preferable for the hygienists and therapists to be dually qualified and to provide training opportunities to enable hygienists to gain therapist qualifications. There is an urgent need to review training for dental technicians nationally and locally. Future training for PCDs should be developed to improve access for areas in the South and West of the region, preferably focused on modular, skill-based, distancelearning/outreach approaches. Responsibility for funding PCD training for the GDS should rest with the WDCs.

More attention needs to be paid to the reasons behind recruitment and retention difficulties of the dental team, cost-effective methods of delivering dental services through dental teams particularly in rural areas, and ways of delivering training more equitably.

Long-term workforce planning is likely to remain an imprecise science, yet it remains important to monitor workforce issues to aid in short-term decision-making.

The authors would like to thank the South West Region NHS Executive for their support in commissioning this survey. 
1 Woolgrave J, Boyles J. Operating auxiliaries in the UK: a review. Community Dent Health 1984; 1:93-99.

2 Baltutis L, Morgan M. The changing role of dental auxiliaries: a literature review. Aust Dent J 1998; 43: 354-358.

3 Kaplan A L. Clinical quality of expanded duty dental auxiliaries. J Public Health Dent 1980; 40: 118-125.

4 Allred $\mathrm{H}, \mathrm{Hobdell} \mathrm{M} \mathrm{H}$. Current experiments in the delivery of dental services. Int Dent J 1974; 24: 457-466

5 GDC. Taking team regulation forward. GDC Gazette 2002; Winter 2001/2:8.

6 Nuffield Foundation. Education and training of personnel auxiliary to dentistry. London: Nuffield Foundation, 1993.

7 Dental Auxiliary Review Group. Report of the Dental Auxiliaries Review Group. London:BDA/JM Consultancy Ltd, 1998.

8 Department of Health. Modernising NHS dentistry implementing the NHS plan. London: DoH, 2000.

9 General Dental Council. Professionals complementary to dentistry. London, GDC 1998.

10 Department of Health. A health service of all the talents: developing the NHS workforce - consultation document on the review of workforce planning. Leeds: DoH, 2000

11 New qualification for nurses. BDA News $2001 ; 14: 5$

12 Dental Strategy Review Group. Towards better dental health - guidelines for the future. London: Department of Health and Social Security, 1981

13 Bronkhorst E M, Truin G J, Batchelor P, Sheiham A. Health through oral health guidelines for planning and monitoring for oral health care: a critical comment on the WHO model. J Public Health Dent 1991; 51: 223-227.

14 AGMETS Dental Subgroup. Report of the Dental Workforce Subgroup. CCCPHD (00) 74. 2000.

15 British Dental Association. Evidence to the House of Commons Health Select Committee. London, British Dental Association, 2001

16 Harris R V, Haycox A. The role of team dentistry in improving access to dental care in the UK. Br Dent J 2001; 190: 353-356.

17 Callis P D, Wohlgemuth B G. Dental hygienists in Scotland - a career survey. Br Dent J 2000; 189: 34-36.

18 Evans C L, Blinkhorn A S. A national survey of dental hygienists. Br Dent J 1982; 153 309-310.

19 Gibbons D, Corrigan M, Newton J T. The working practices and job satisfaction of dental therapists findings of a national survey. Br Dent J 2000; 189: 435-438.

20 Hillam D. Career patterns of dental hygienists qualifying from the Liverpool Dental School of Dental Hygiene. Br Dent J 1989; 166: 310-311.

21 Holt R D, Murray J J. Therapists survey. Br Dent J2001: 190:3.

22 Gibbons D E, Corrigan M, Newton J T. A national survey of dental hygienists: working patterns and job satisfaction. Br Dent J 2001; 190: 207-210.

23 Elley K, Taylor K, Langford J. Dental practice workforce: developing a baseline picture in the West Midlands Region. Report on a survey undertaken by Larket and Opinion Research International in 1997. NHS West Midlands, 1998.

$24 \operatorname{Tan} \mathrm{R}$ T, Burke FJ T. Response rates to questionnaires mailed to dentists. A review of 77 publications. Int Dent J 1997: 47: 349-354.

25 Murray J J. Better opportunities for women dentists: a review of the contribution of women dentists to the workforce. Br Dent J 2002; 192: 191-196.

26 Adkins J. Gendered work: sexuality, family and the labour market. Buckingham: Open University Press, 1995

27 Douglass C W, Cole K 0. The supply of dental manpower in the United States. J Dent Educ 1979; 43: 287-302.

28 Croucher R, Osborne D, Marcenes W, Sheiham A. Burnout and issues of the work environment reported by general dental practitioners in the United Kingdom. Community Dent Health 1998; 15: 40-43.

29 Osborne D, Croucher R. Levels of burnout in general dental practitioners in the South East of England. BrDentJ 1995; 177: 372-377.

30 Lewis D W. Dental manpower supply and demand projections and changing demography and dental disease. J Can Dent Assoc 1986; 52:33-40.

31 McGrath C, Bedi R, Dhawan N. Who has difficulty in registering with an NHS dentist? - A national survey. Br Dent J 2001; 191: 682-685.

32 Half-term report from the elected members of the General Dental Council. Br DentJ 1979; 147: 217-223.

33 Newton J T, Gibbons D E. Vacant posts reported in dental practice: implications for human resource planning. Br Dent J2002; 192: 37-39.

34 Gibson B, Freeman R, Elkins R. The role of the dental nurse in general practice. Br Dent J 1999: 186: 213-215

35 Newton JT, Gibbons D E. Levels of career satisfaction amongst dental healthcare professionals: comparison of dental therapists, dental hygienists and dental practitioners. Community Dent Health 2001: 18: 172-176.

36 Newton J T, Buck D, Gibbons D E. Workforce planning in dentistry: the impact of shorter and more varied career patterns. Community Dent Health 2001; 18: 236-241.

37 DeFriese G H, Barker B D. The status of dental manpower research. J Dent Educ 1983; 47: 728-737.

38 Batchelor P. Can we plan workforce requirements? Community Dent Health 2002; 19: 129-130.

39 Chief Dental Officer. NHS Dentistry: options for change. London, Department of Health, 2002

40 Audit Commission. Dentistry. Primary dental care services in England and Wales. London: Audit Commission, 2002.

41 Allen C. Dental nurse workforce and training needs in general dental practice. Community Dental Health 2002; 19: 195.

\section{BDA Information Centre Services}

\section{Did you know?}

- As a BDA member you can gain access to one of the best dental information services in the world

- You don't have to be based in London to use the service

- You can borrow books, videos and information packages

- You can borrow up to eight items via the postal system

The only cost to you is the cost of the return postage. If you're not sure what to request then telephone us and we can advise you.

- You are entitled to free MeduINE searches Telephone us with a subject and we will send you a list of relevant references with abstracts.

- You can request photocopies of journal articles
There is a small charge for this service and you need to fill in a Photocopy Request Form first. Telephone us if you would like one of these forms.

- BDA Members can view the latest Current Dental Titles on our web site free of charge. These are Medline-based lists of references on eight areas of dentistry which are available to BDA members only on the our web site and which are updated twice yearly. Just use your password with which you have been issued.

For further details of any of these services dial 02075634545 .

Contact us via e-mail at:

Infocentre@bda-dentistry.org.uk

Visit the Information Centre web pages at: http://www-dentistry.org.uk/infocntr/index.html 